\title{
MDM2 promotes the proliferation and inhibits the apoptosis of pituitary adenoma cells by directly interacting with p53
}

\author{
Yibiao Wang1, Jiannong Zhao', Chaocai Zhang², Pengchen Wang', Chuixue Huang², Hao Peng² \\ ${ }^{1}$ Department of Neurosurgery, Jinan University First Affiliated Hospital, Tianhe District, Guangzhou, China \\ ${ }^{2}$ Department of Neurosurgery, Hainan General Hospital, Xiuying District, Haikou, Hainan Province, China
}

\begin{abstract}
Introduction: Pituitary adenomas constitute one of the most common intracranial tumours. The mouse double minute 2 homologue (MDM2) is considered as an important oncogene in many tumours, but it has been little studied in pituitary adenomas and the mechanism is not well understood. The purpose of this study was to investigate the function of MDM2 and its primary mechanism of action in pituitary adenoma cells.

Material and methods: The expression of MDM2 in pituitary adenoma cell lines and normal cells was determined by real-time polymerase chain reaction (RT-PCR). The proliferation and apoptosis of pituitary adenoma cells after inhibition of MDM2 expression were detected by MTS and flow cytometry, respectively. The protein expressions of MDM2 and p53 were detected by western blot. Co-IP was used to detect the direct binding between MDM2 and p53.

Results: The results of RT-PCR showed that MDM2 was significantly up-regulated in pituitary adenoma cell lines. Inhibition of MDM2 suppressed the proliferation and promoted apoptosis of pituitary adenoma cells. However, inhibiting the expression of MDM2 can promote the protein expression of p53. The results of co-IP showed that MDM2 interacted with p53 by direct combination. Then, we inhibited the expressions of p53 and MDM2 simultaneously in the pituitary adenoma cells by co-transfecting siRNAs, and the results showed that, compared with the group that inhibited MDM2 alone, cell proliferation of the co-transfected group increased and apoptosis of the cotransfected group decreased, which was similar to the NC group.

Conclusions: Taken together, these results suggest that MDM2 promoted the proliferation and inhibited the apoptosis of pituitary adenoma cells by directly interacting with p53 in pituitary adenoma cells. Therefore, MDM2-p53 may serve as a novel marker and therapeutic target for pituitary adenomas. (Endokrynol Pol 2020; 71 (5): 425-431)
\end{abstract}

Key words: pituitary adenomas; MDM2; proliferation; apoptosis; p53

\section{Introduction}

Pituitary adenoma is a common primary brain tumour, accounting for about $22.5 \%$ of intracranial tumours, ranking third in incidence, but only $0.1-0.2 \%$ were diagnosed as pituitary carcinoma $[1,2]$. There are many types of pituitary adenomas depending on the hormone secretion. In China, $42.70 \%$ of pituitary carcinomas did not secrete hormones, while the others secreted a variety of hormones, such as follicle-stimulating hormone, prolactin, growth hormone, and adrenocorticotropin [3]. Due to the different types of pituitary adenoma, its pathogenesis may also be diverse. However, one point is recognised: the pathogenesis of pituitary adenoma may include the mutation and expression of early genes and pituitary-specific oncogenes, which is a complex event involving multiple molecules. Therefore, elucidating the molecular pathogenesis of pituitary adenoma and identifying reliable biomarkers for diagnosis and treatment are still the key points in this field.

The mouse double minute 2 homologue (MDM2) gene is an oncogene locating in chromosome 12q13214 [4]. In many cancers, MDM2 has been proven to be an oncogene overexpressed in cancer tissues. For example, in malignant pleural mesothelioma, MDM2 is a prognostic factor associated with poor survival and a predictive marker for a platin pemetrexed therapy [5, 6]. In breast cancer, MDM2 induces epithelial-to-mesenchymal transition (EMT) in vitro and in vivo, and the expression of MDM2 can lead to different tumour processes in different types of breast cancer $[7,8]$, while in pituitary adenoma, little research has been done on MDM2. Suliman et al. first found that MDM2 was expressed in the cytoplasm of tumours as a downstream 
gene of p53, indicating that MDM2 may be a functional factor in pituitary adenoma [9]. Furthermore, Yao X et al. found that MDM2 may be a biomarker and potential drug target for pituitary adenoma treatment [10]. However, the mechanism of MDM2 in pituitary adenoma has not been studied thoroughly and clearly.

At present, the mechanism of MDM2 acting as a proto-oncogene in tumourigenesis is mainly focused on its binding with p53 gene, which are often inseparable from each other. P53 and MDM2 regulate p53 protein activity and MDM2 gene expression by forming a self-regulating negative feedback loop [11]. In many cancers, the negative feedback loop of MDM2-p53 plays an important regulatory role. Disruption of the MDM2-p53 loop function by introducing molecule could suppress hepatocellular carcinoma tumourigenesis [12]. A small molecule inhibitor of MDM2-p53 could enhance the radio-sensitivity of gastric adenocarcinoma [13]. Similarly, another inhibitor of MDM2-p53 could suppress cell proliferation in nasopharyngeal carcinoma [14]. However, the function and mechanism of MDM2-p53 negative feedback loop in pituitary adenoma have not been reported before.

Therefore, on the basis of the above, our study conducted a detailed study on the expression and function of MDM2 in pituitary adenoma cells. In addition, the mechanism of MDM2's influence on pituitary adenoma cells through directly binding p53 was also verified. Our study provided a research basis for MDM2 as a possible therapeutic target of pituitary adenoma.

\section{Material and methods}

\section{Cell lines}

Mouse pituitary adenoma cell lines AtT-20 (CCL-89) was purchased from the American type culture collection (ATCC, USA) which has adrenocorticotropic hormone (ACTH) activity. Mouse pituitary adenoma cell lines GT1-1 was purchased from China Academy of Medical Sciences Cell Resource Centre, which has luteinising hormone-releasing hormone (LHRH) activity. Mouse pituitary cell MPC was purchased from ScienCell (USA). MPC and GT1-1 cells were cultured in high-glucose Dulbecco's modified eagle's medium (DMEM, Gibco, Life Technologies, Gaithersburg, MD, USA) supplemented with $10 \%$ horse serum (Gibco, Life Technologies, Gaithersburg, MD, USA) and 2.5\% foetal bovine serum (FBS, Gibco, Life Technologies, Gaithersburg, MD, USA). AtT-20 cells were cultured in F-12K medium (Gibco, Life Technologies, Gaithersburg, MD, USA) supplemented with 10\% horse serum (Gibco, Life Technologies, Gaithersburg, MD, USA) and 2.5\% FBS (Gibco, Life Technologies, Gaithersburg, MD, USA). All of them were incubated at $37^{\circ} \mathrm{C}$ in a humidified atmosphere with $5 \% \mathrm{CO}_{2}$.

\section{$R T-q P C R$}

We extracted total RNAs of cell lines according to the RNeasy kit (Qiagen, Inc., Valencia, CA, USA) instructions. The reverse transcription was reacted using the One step cDNA synthesis kit (Takara). Quantitative real-time PCR (RT-qPCR) was performed on the ABI7500 real-time PCR system (Applied Biosystems) using the SYBR ${ }^{\circledR}$ premix kit (Takara). GAPDH was used as the internal con- trol. We applied 2- CT to calculate the relative expression quantity. The primers of MDM2 and GAPDH were listed as follows: MDM2 F: 5'-AAGATGCGCGGGAAGTAGC-3' ' R: 5' -GGTTTTGGTCTAACCTGGAGGC-3'; GAPDH F: 5'- TGGCCGTGGGGCTGCCCAG-3', R: 5'- GGAAGGCCATGCCAGTGAGC-3'.

\section{Transfection}

The sequences of siRNA were listed: si-MDM2: 5'-GUGUGUUAUUAGUUCUUAAAU-3', si-p53: 5'-ACUACAAGUACAUGUGUAAUA-3' and negative control (NC): 5'-UUCUCCGAACGUGUCACGUTT-3'. All of those were purchased from Sigma. Inc. The siRNAs were transfected into cells at a concentration of $50 \mathrm{nM}$ by lipofectamine transfection reagent (Invi

\section{Cell proliferation assay}

Cells (2000 cells/well, three replicates per group) in the 96-well plates were cultured for 24,48 , and $72 \mathrm{~h}$, respectively. Cell proliferation was determined by MTS using cell proliferation assay kit (Abcam, Cambridge, MA, England). $20 \mu \mathrm{L}$ MTS reagent was added into each well and incubated for $4 \mathrm{~h}$ at $37^{\circ} \mathrm{C}$. After shaking briefly, the absorbance of each plate was measured at OD $=490 \mathrm{~nm}$.

\section{Cell apoptosis assay}

Cell apoptosis was assayed by Annexin v-FITC Apoptosis Detection Kit I (BD Biosciences, Franklin Lakes, NJ, USA). Cell culture medium was transferred to $15 \mathrm{ml}$ conical tubes and placed on ice. The cells in the 24-well plates were lightly moistened with $2 \mathrm{~mL}$ PBS. After removing the PBS, $0.5 \mathrm{ml} 0.25 \%$ trypsin was added to the plates for incubating until cells were completely detached from the culture wall. The cells were gently suspended in the $1 \times$ binding buffer $(0.1 \mathrm{M}$ Hepes/ $/ \mathrm{NaOH}$ pH 7.4, $\left.1.4 \mathrm{M} \mathrm{NaCl}, 25 \mathrm{mM} \mathrm{CaCl}_{2}\right) .0 .5 \mathrm{~mL}$ of the cell suspension was transferred from the cell culture plate $(5 \times 105$ cells $)$ to a clean centrifuge tube. $1.25 \mu \mathrm{l}$ Annexin v-FITC (BD Biosciences, Franklin Lakes, NJ, USA) was added at room temperature $\left(18-24^{\circ} \mathrm{C}\right)$ in the dark for 15 mins and mixed with $10 \mu$ PI for 5 mins. Samples were then diluted with $400 \mu \mathrm{l} 1 \times$ binding buffer and analysed by flow cytometry (BD Biosciences, Franklin Lakes, NJ, USA).

\section{Western blot analysis}

Lysed cells for 30 mins at $4^{\circ} \mathrm{C}$ in a buffer containing RIPA (Beyotime, Shanghai, China) and then centrifuged at $12,000 \mathrm{rpm}$ for $10 \mathrm{~min}$ at $4^{\circ} \mathrm{C}$. Protein concentrations were determined by the Bicinchoninic acid (BCA) protein assay kit (Sigma Aldrich Chemical Company, St. Louis, MO, USA). For electrophoresis, $30 \mu \mathrm{g}$ total protein was added to every lane, which was separated in Sodium dodecyl sulphate polyacrylamide (SDS-PAGE, separate gel $10 \%$, concentrate gel $6 \%$ ) gel and then transferred to a polyvinylidene fluoride (PVDF) membrane. Then, after blocking the membranes for $2 \mathrm{~h}$ at room temperature, the membranes were incubated with anti-MDM2 (Abcam, Cambridge, MA, England, ab226939), anti-p53 (Abcam, Cambridge, MA, England, ab131442), or anti-GAPDH (Abcam, Cambridge, MA, England, ab8245) overnight. Bands visualisation was carried out by enhanced chemical luminescence reagent (PerkinElmer Life Sciences, MA, USA) after secondary antibody (Invitrogen) conjugated Horseradish peroxidase (HRP) incubation. The density ratios of MDM2/GAPDH and p53/GAPDH were the relative levels of MDM2 and p53.

\section{Co-immunoprecipitation (co-IP) assay}

Total protein was extracted from cells $-800 \mu \mathrm{g}$ total protein, incubated at $4^{\circ} \mathrm{C}$ overnight with anti-MDM2 (Abcam, Cambridge, MA, England, ab226939). Then, protein A agarose beads $(20 \mu \mathrm{L})$ were mixed and incubated for $2 \mathrm{~h}$. The mixture above was then centrifuged and washed three times with PBS. Western blotting was performed to detect $\mathrm{p} 53$ protein of precipitation. 


\section{Statistical analysis}

All experimental data were analysed using SPSS 17.0 (SPSS Inc., Chicago, IL, USA). All the final results were presented as mean \pm standard deviation. Student's t-test was used to determine the differences between two groups. $p<0.05$ was considered as the level of statistical significance.

\section{Results}

\section{MDM2 was up-regulated in pituitary adenoma cell lines}

In order to determine whether MDM2 was differentially expressed in pituitary adenomas cell lines, pituitary cell MPC, pituitary adenoma cancer cells GT1-1 and AtT-20 were analysed by the RT-PCR. The result showed that the expression of MDM2 was significantly increased in pituitary adenoma cells in comparison with MPC cells (Fig. 1).

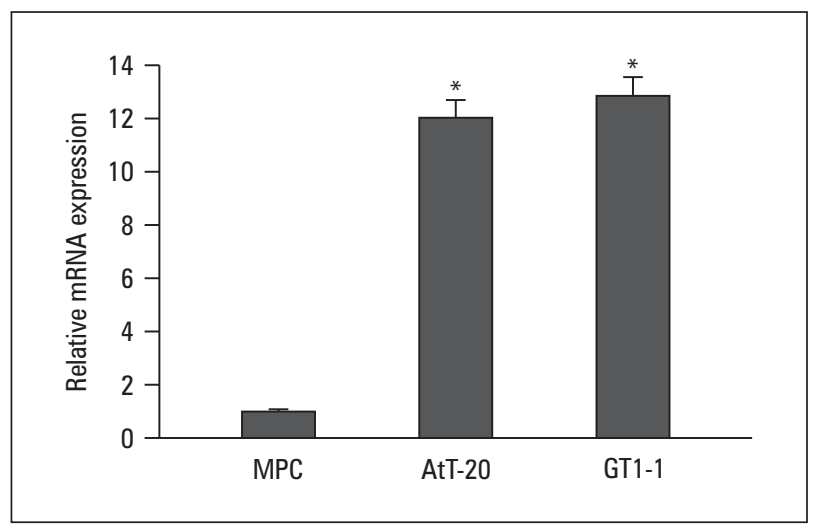

Figure 1. The mouse double minute 2 homologue (MDM2) was up-regulated in pituitary adenoma cell lines. Real-time quantitative polymerase chain reaction $(R T-q P C R)$ was performed to evaluate the expression of MDM2 in pituitary adenomas cell lines and normal cell lines $\left({ }^{*} p<0.05\right)$

\section{MDM2 inhibition suppressed proliferation of pituitary adenomas cell lines}

To evaluate the function of MDM2 in pituitary adenoma cells, the expression of MDM2 was decreased by transfecting siRNA of MDM2 into both AtT-20 and GT1-1 cells. The expression of MDM2 was confirmed by western blot. As shown in Figure 2A MTS was used to investigate the proliferation of pituitary adenomas cells. Inhibition of MDM2 significantly decreased the proliferation of pituitary adenoma cells as compared to the negative control (Fig. 2B).

\section{MDM2 inhibition promoted apoptosis of pituitary adenoma cell lines}

Flow cytometry was used to further investigate the apoptosis of all the groups. Inhibition of MDM2 significantly promoted the apoptosis of pituitary adenoma cells as compared to the negative control (Fig. 3) $(p<0.05)$. These results suggest that MDM2 could promote the vitality of AtT-20 and GT1-1 cells.

\section{MDM2 negatively regulated p53 through direct binding in pituitary adenoma cell lines}

In order to verify the relationship between MDM2 and p53 in pituitary adenoma cells, we firstly examined the p53 protein level when transfecting siRNA of MDM2 in AtT-20 and GT1-1 cells. The results of western blot showed that the protein level of p53 was increased when MDM2 protein expression was decreased by siRNA (Fig. 4A). Furthermore, we used a co-IP experiment to detect whether MDM2 directly binds to p53 in pituitary adenoma cells. The precipitation pulled down by MDM2 antibody was analysed by western blot; positive p53 protein was shown in both AtT-20 and GT1-1 cells (Fig. 4B). These results suggest that

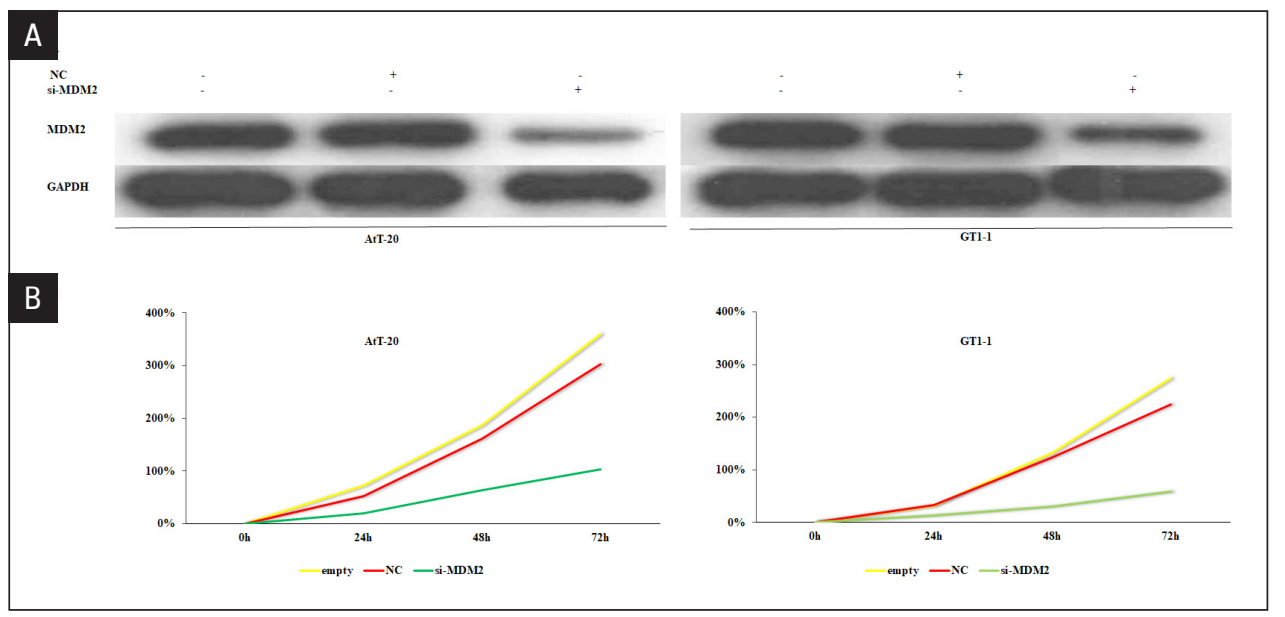

Figure 2. Inhibition of the mouse double minute 2 homologue (MDM2) suppressed the proliferation of pituitary adenomas cells. A. Western blot was used to detect the protein level of MDM2 when the si-MDM2 and its NC were transfected into AtT-20 and GT1-1 cells, respectively. B. Cell proliferation was detected by MTS assay 


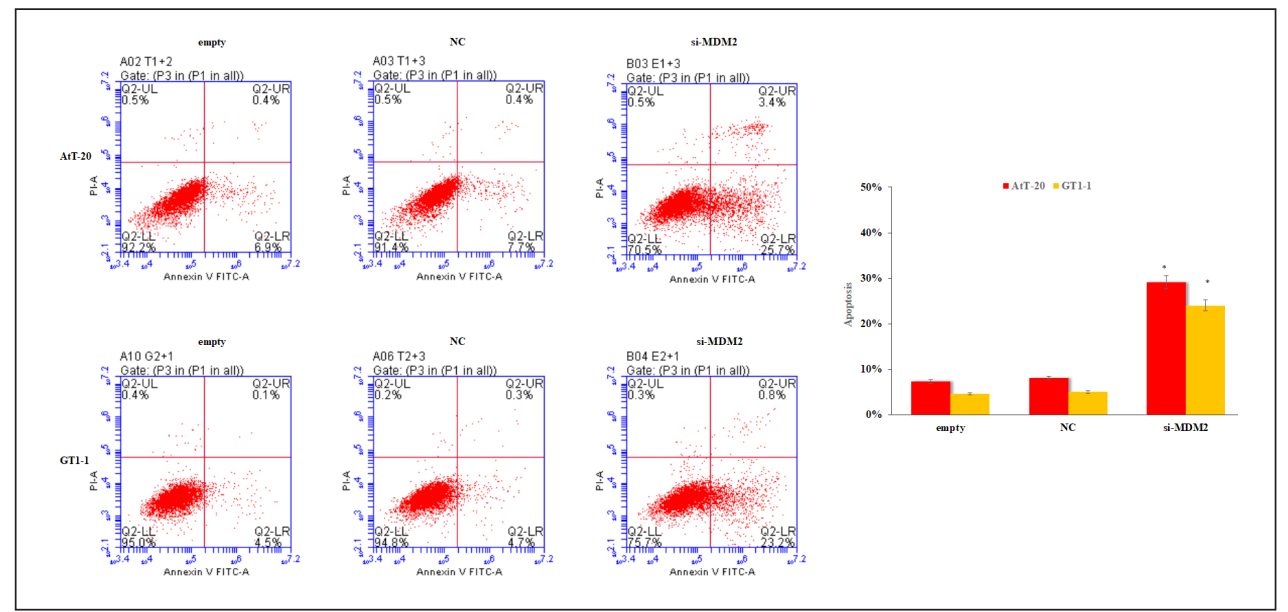

Figure 3. Inhibition of the mouse double minute 2 homologue (MDM2) promoted the apoptosis of pituitary adenomas cells. Cell apoptosis was detected by flow cytometry when the si-MDM2 and its NC were transfected into AtT-20 and GT1-1 cells, respectively $\left({ }^{*} p<0.05\right)$

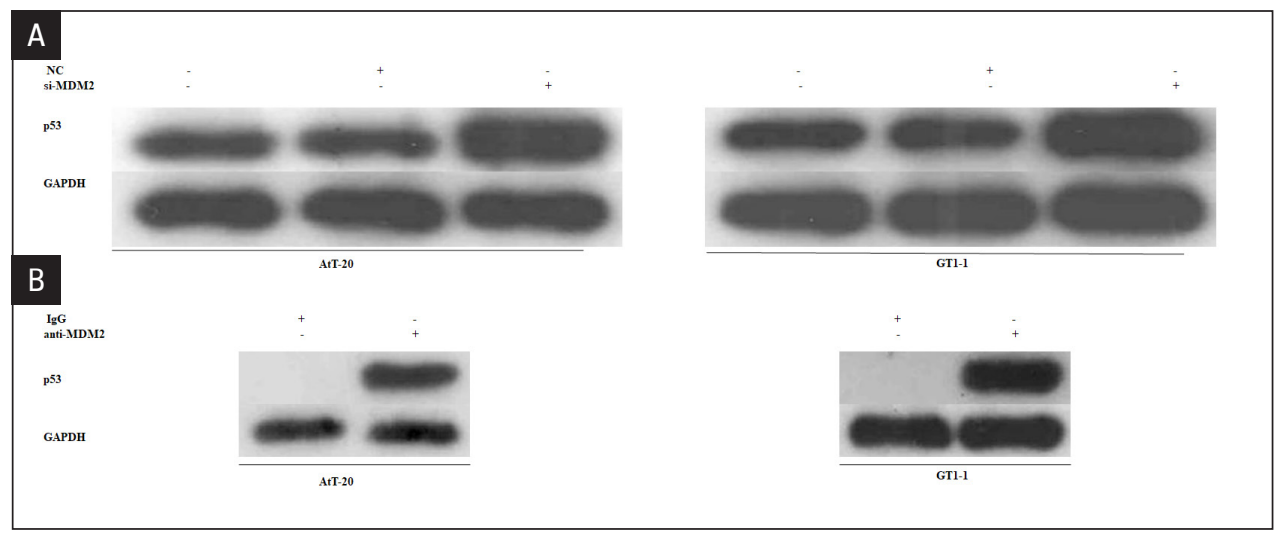

Figure 4. The mouse double minute 2 homologue (MDM2) negatively regulated $p 53$ through direct binding in pituitary adenomas cell lines. A. The protein level of $p 53$ was detected when the expression of MDM2 was inhibited. B. The direct binding between MDM2 and p53 was array by Co-IP. The precipitation pulled down by MDM2 antibody was analysis by western blot using anti-p53

MDM2 directly interacts with p53 in pituitary adenoma cells.

\section{P53 inhibition could counteract the effect on proliferation and apoptosis of pituitary adenoma cells induced by MDM2 inhibition}

To further verify the effect of this direct correlation between MDM2 and p53 on pituitary adenoma cells, we co-transfected siRNA of MDM2 and siRNA of p53 into pituitary adenomas cells. Western blot was used to detect the protein level of MDM2 and p53 using GAPDH as internal parameters. MTS assay was used to detect the cell proliferation of each group, and flow cytometry was used to detect cell apoptosis. The results showed that p53 expression was decreased upon co-transfection of two siRNAs (Fig. 5A), while the proliferation (Fig. 5B) was enhanced and the apoptosis (Fig. 5C) was decreased comparing to the group of si-MDM2 alone. These results suggest that the inhibition of p53 in pituitary adenomas cells could offset the affection on proliferation and apoptosis caused by the inhibition of MDM2.

\section{Discussion}

The mouse double minute 2 homologue was first cloned from the double-minute chromosome of spontaneously transformed mouse cell lines [15]. The mouse double minute 2 homologue was subsequently shown to have oncogenic functions and to be involved in tumourigenesis $[16,17]$. In pituitary adenomas, Suliman et al. first found that MDM2 may be a functional factor in pituitary adenoma [9]. Furthermore, Yao $\mathrm{X}$ et al. found that MDM2 may be a biomarker and potential drug target for non-functioning pituitary adenoma treatment [10]. However, there has been no in-depth study on the effect of MDM2 in pituitary adenoma cells. 


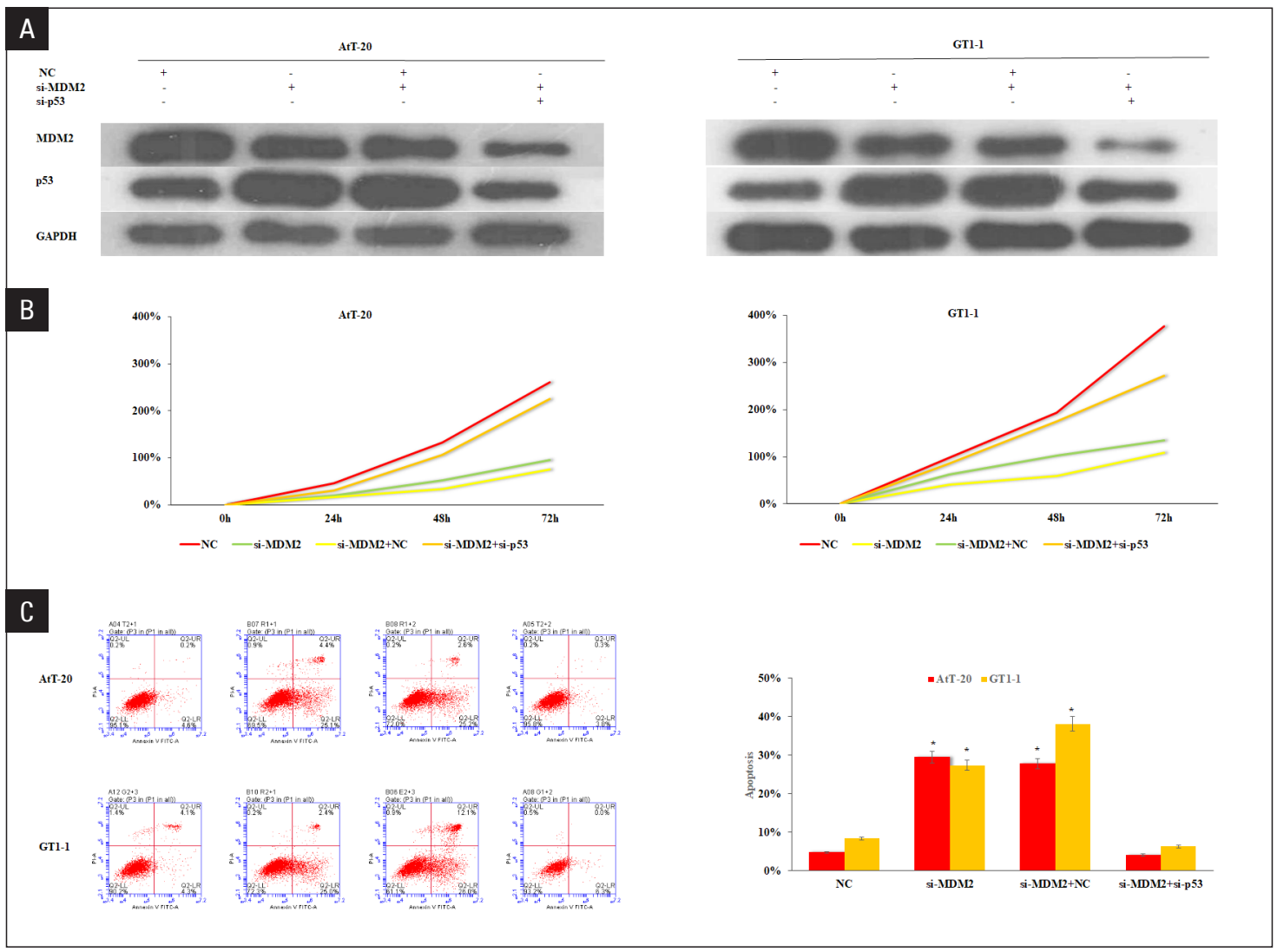

Figure 5. P53 inhibition could counteract the effect on proliferation and apoptosis of pituitary adenoma cells induced by the mouse double minute 2 homologue (MDM2) inhibition. We co-transfected si-MDM2 with si-p53 or its NC control into pituitary adenoma cells. A. Western blot assay was performed to detect the MDM2 and p53 expression on AtT-20 cells and GT1-1 cells, using GAPDH as an internal reference. B. Cell proliferation was detected by MTS assay. C. Cell apoptosis was measured by flow cytometry $\left({ }^{*} p<0.05\right)$

Our study examined the expression of MDM2 in pituitary adenoma cells and confirmed that MDM2 was highly expressed in pituitary adenoma cells compared with normal cells. Moreover, after interfering with the expression of MDM2, the proliferation ability of pituitary adenoma cells was inhibited and apoptosis was promoted. This suggests that MDM2 also plays a role as a proto-oncogene in pituitary adenoma cells and is involved in tumourigenesis.

P53 is a powerful tumour suppressor, and more than half of human tumours have p53 mutations [18]. The MDM2 gene regulated the activity of p53 protein by binding to the N-terminus of p53 [19]. P53 and MDM2 always form a self-regulating negative feedback loop to regulate cell function [11]. When MDM2 expression decreases, p53 expression increases, which binds to the P2 promoter of MDM2 to induce MDM2 expression in turn [20]. MDM2-p53 has been reported to play key roles in tumour suppressive [21]. In our study, we found that higher expression of MDM2 could directly bind to p53 protein in pituitary adenoma cells, and that interfering with the expression of p53 could counteract the proliferation inhibition and apoptosis promotion of cancer cells caused by the inhibition of MDM2. It has been suggested that MDM2-p53 plays an important regulatory role in pituitary adenoma because it does so in other tumours.

Based on our studies and existing reports, it can be seen that MDM2 is highly expressed in pituitary adenoma, and p53 is still an important link in its mechanism. Also, MDM2-p53 is an important pathway affecting the occurrence of pituitary adenoma. Hence, it is easy to conclude that targeting the MDM2-p53 negative feedback loop would be a good strategy for pituitary adenoma treatment.

In fact, a number of compounds or small molecules targeting MDM2-p53 have been used by researchers to test the efficacy of treatments in different cancers. Because overexpression of MDM2 reduces the ability of p53, MDM2 inhibitors have been used to activate p53 activity for cancer therapy in recent years [22]. Vassilev et al. first reported Nutlins as a small-molecule inhibitor of MDM2, which could induce p53 accumulation and promote apoptosis of tumour cells [23]. The MDM2 inhibitor RG7112 discovered by scientists of the Roche company has advanced to clinical trials [24]. Other MDM2 inhibitors, such as SAR405838, MK-8242, NVP-CGM097, and AMG232, have also been studied in clinical trials [25-2 


\section{Conclusions}

Our results found that the negative feedback loop of MDM2-p53 might still play an important role in pituitary adenoma, which indicates that the small molecule inhibitors reported previously have the same anticancer effect on pituitary adenoma. This provided a feasible strategy for the target treatment of pituitary adenoma. This study has limitations because we only detected the direct binding between MDM2 and p53 in pituitary adenoma. Other mechanisms, such as MDM2, which acts as an E3 ubiquitin ligase to promote p53 degradation, MDM2, which promotes p53 to transfer from nuclear to cytoplasmic, and p53, which regulates the expression of MDM2 and other downstream factors as a transcription factor, all need further research. In general, a detailed study on the regulation mechanism of MDM2 through p53 in pituitary adenoma cells can provide new strategies for the treatment of pituitary adenoma in the future.

\section{Acknowledgments}

Not applicable.

\section{Funding}

The study was supported by Hainan Provincial Natural Science Foundation for Youths (819QN346).

\section{Authors' contributions}

Yibiao Wang designed the experiment, and Hao Peng supervised the experimental performance. All authors participated in the experiments and data analysis. Hao Peng finished the data interpretation, and Yibiao Wang wrote the paper. All authors read and approved this paper.

\section{Disclosure statement}

No potential conflict of interest was reported by the authors.

\section{Ethics statement}

Not applicable.

\section{References}

1. Pichard C, Gerber S, Laloi M, et al. Pituitary carcinoma: report of an exceptional case and review of the literature. J Endocrinol Invest. 2002; 25(1): 65-72, doi: 10.1007/BF03343963, indexed in Pubmed: 11883868 .

2. Ezzat S, Asa SL, Couldwell WT, et al. The prevalence of pituitary adenomas: a systematic review. Cancer. 2004; 101(3): 613-619, doi: 10.1002/cncr.20412, indexed in Pubmed: 15274075.

3. Zhu X, Wang Y, Zhao X, et al. Incidence of Pituitary Apoplexy and Its Risk Factors in Chinese People: A Database Study of Patients with Pituitary Adenoma. PLoS One. 2015; 10(9): e0139088, doi: 10.1371/journal. pone.0139088, indexed in Pubmed: 26407083.

4. Oliner JD, Kinzler KW, Meltzer PS, et al. Amplification of a gene encoding a p53-associated protein in human sarcomas. Nature. 1992; 358(6381): 80-83, doi: 10.1038/358080a0, indexed in Pubmed: 1614537.
5. Mairinger FD, Walter RFH, Ting S, et al. Mdm2 protein expression is strongly associated with survival in malignant pleural mesothelioma. Future Oncol. 2014; 10(6): 995-1005, doi: 10.2217/fon.13.261, indexed in Pubmed: 24941985.

6. Walter RFH, Mairinger FD, Ting S, et al. MDM2 is an important prognostic and predictive factor for platin-pemetrexed therapy in malignant pleural mesotheliomas and deregulation of P14/ARF (encoded by CDKN2A) seems to contribute to an MDM2-driven inactivation of P53. Br J Cancer. 2015; 112(5): 883-890, doi: 10.1038/bjc.2015.27, indexed in Pubmed: 25668009.

7. Lu X, Yan C, Huang Yi, et al. Mouse double minute 2 (MDM2) upregulates Snail expression and induces epithelial-to-mesenchymal transition in breast cancer cells in vitro and in vivo. Oncotarget. 2016; 7(24): 37177-37191, doi: 10.18632/oncotarget.9287, indexed in Pubmed: 27184007.

8. Gao C, Xiao Gu, Piersigilli A, et al. Context-dependent roles of MDMX (MDM4) and MDM2 in breast cancer proliferation and circulating tumor cells. Breast Cancer Res. 2019; 21(1): 5, doi: 10.1186/s13058-018-1094-8, indexed in Pubmed: 30642351.

9. Suliman M, Royds J, Cullen D, et al. Mdm2 and the p53 pathway in human pituitary adenomas. Clin Endocrinol (Oxf). 2001; 54(3): 317-325, doi: 10.1046/j.1365-2265.2001.01195.x, indexed in Pubmed: 11298083.

10. Yao X, Gao H, Li C, et al. Analysis of Ki67, HMGA1, MDM2, and RB expression in nonfunctioning pituitary adenomas. J Neurooncol. 2017; 132(2): 199-206, doi: 10.1007/s11060-016-2365-9, indexed in Pubmed: 28255749.

11. Wu X, Bayle JH, Olson D, et al. The p53-mdm-2 autoregulatory feedback loop. Genes Dev. 1993; 7(7A): 1126-1132, doi: 10.1101/gad.7.7a.1126, indexed in Pubmed: 8319905.

12. Ye J, Liang R, Bai T, et al. RBM38 plays a tumor-suppressor role via stabilizing the p53-mdm2 loop function in hepatocellular carcinoma. J Exp Clin Cancer Res. 2018; 37(1): 212, doi: 10.1186/s13046-018-0852-x, indexed in Pubmed: 30176896.

13. Yi H, Yan X, Luo Q, et al. A novel small molecule inhibitor of MDM2-p53 (APG-115) enhances radiosensitivity of gastric adenocarcinoma. J Exp Clin Cancer Res. 2018; 37(1): 97, doi: 10.1186/s13046-018-0765-8, indexed in Pubmed: 29716622

14. Fan X, Wang Y, Song J, et al. MDM2 inhibitor RG7388 potently inhibits tumors by activating p53 pathway in nasopharyngeal carcinoma. Cancer Biol Ther. 2019; 20(10): 1328-1336, doi: 10.1080/15384047.2019.1638677, indexed in Pubmed: 31311404.

15. Cahilly-Snyder L, Yang-Feng T, Francke U, et al. Molecular analysis and chromosomal mapping of amplified genes isolated from a transformed mouse 3T3 cell line. Somat Cell Mol Genet. 1987; 13(3): 235-244, doi: 10.1007/BF01535205, indexed in Pubmed: 3474784.

16. Wade M, Li YC, Wahl GM. MDM2, MDMX and p53 in oncogenesis and cancer therapy. Nat Rev Cancer. 2013; 13(2): 83-96, doi: 10.1038/nrc3430, indexed in Pubmed: 23303139.

17. Senturk E, Manfredi JJ. Mdm2 and tumorigenesis: evolving theories and unsolved mysteries. Genes Cancer. 2012; 3(3-4): 192-198, doi: 10.1177/1947601912457368, indexed in Pubmed: 23150752.

18. Olivier M, Hollstein M, Hainaut P. TP53 mutations in human cancers: origins, consequences, and clinical use. Cold Spring Harb Perspect Biol. 2010; 2(1): a001008, doi: 10.1101/cshperspect.a001008, indexed in Pubmed: 20182602.

19. Piette J, Neel H, Maréchal V. Mdm2: keeping p53 under control. Oncogene. 1997; 15(9): 1001-1010, doi: 10.1038/sj.onc.1201432, indexed in Pubmed: 9285554.

20. Zhao $\mathrm{Y}, \mathrm{Yu} \mathrm{H}, \mathrm{Hu} \mathrm{W}$. The regulation of MDM2 oncogene and its impact on human cancers. Acta Biochim Biophys Sin (Shanghai). 2014; 46(3): 180-189, doi: 10.1093/abbs/gmt147, indexed in Pubmed: 24389645.

21. Hanahan D, Weinberg RA. Hallmarks of cancer: the next generation. Cell. 2011; 144(5): 646-674, doi: 10.1016/j.cell.2011.02.013, indexed in Pubmed: 21376230.

22. Zhao Y, Aguilar A, Bernard D, et al. Small-molecule inhibitors of the MDM2-p53 protein-protein interaction (MDM2 Inhibitors) in clinical trials for cancer treatment. J Med Chem. 2015; 58(3): 1038-1052, doi: 10.1021/jm501092z, indexed in Pubmed: 25396320.

23. Vassilev L. Small-Molecule Antagonists of p53-MDM2 Binding: Research Tools and Potential Therapeutics. Cell Cycle. 2014; 3(4): 417-419, doi: 10.4161/cc.3.4.801, indexed in Pubmed: 15004525.

24. Tovar C, Graves B, Packman K, et al. MDM2 small-molecule antagonist RG7112 activates p53 signaling and regresses human tumors in preclinical cancer models. Cancer Res. 2013; 73(8): 2587-2597, doi: 10.1158/0008-5472.CAN-12-2807, indexed in Pubmed: 23400593.

25. Bill KL, Garnett J, Meaux I, et al. SAR405838: A Novel and Potent Inhibitor of the MDM2:p53 Axis for the Treatment of Dedifferentiated Liposarcoma. Clin Cancer Res. 2016; 22(5): 1150-1160, doi: 10.1158/1078-0432. CCR-15-1522, indexed in Pubmed: 26475335.

26. Wagner AJ, Banerji U, Mahipal A, et al. Phase I Trial of the Human Double Minute 2 Inhibitor MK-8242 in Patients With Advanced Solid Tumors. J Clin Oncol. 2017; 35(12): 1304-1311, doi: 10.1200/JCO.2016.70.7117, indexed in Pubmed: 28240971. 
27. Holzer P Masuya K, Furet $\mathrm{P}$ et al Discovery of a Dihydroisoquinolinone Derivative (NVP-CGM097): A Highly Potent and Selective MDM2 Inhibior Undergoing Phase 1 Clinical Trials in p53wt Tumors. J Med Chem. 2015; 58(16): 6348-6358, doi: 10.1021/acs.jmedchem.5b00810, indexed in Pubmed: 26181851.
28. Canon $\mathrm{J}$, Osgood $\mathrm{T}$, Olson $\mathrm{SH}$, et al. The MDM2 Inhibitor AMG 232 Demonstrates Robust Antitumor Efficacy and Potentiates the Activity of p53-Inducing Cytotoxic Agents. Mol Cancer Ther. 2015; 14(3): 649-658, doi: 10.1158/1535-7163.MCT-14-0710, indexed in Pubmed: 25567130. 